This document is the Accepted Manuscript version of the following article: Yangbo Deng, Hongwei $\mathrm{Wu}$, and Fengmin Su, 'Combustion and exhaust emission characteristics of low swirl injector', Applied Thermal Engineering, Vol. 110, pp. 171-180, first published online 28 August 2016.

This manuscript version is made available under the CC-BY-NC-ND 4.0 license http://creativecommons.org/licenses/by-nc-nd/4.0/

The version of record is available online at doi: http://dx.doi.org/10.1016/j.applthermaleng.2016.08.169

(c) 2016 Elsevier Ltd. All rights reserved. 


\title{
Combustion and exhaust emission characteristics of low swirl injector
}

\author{
Yangbo Deng ${ }^{\mathrm{a}, *}$, Hongwei $\mathrm{Wu}^{\mathrm{b}}$, Fengmin $\mathrm{Su}^{\mathrm{a}}$ \\ ${ }^{a}$ Marine Engineering College, Dalian Maritime University, Dalian116026, China \\ ${ }^{b}$ Department of Mechanical and Construction Engineering, Faculty of Engineering and Environment, \\ Northumbria University, NE1 8ST, United Kingdom
}

${ }^{*}$ Corresponding author. Email: dengyb1970@dlmu.edu.cn;

\begin{abstract}
The present experimental study aims to investigate the combustion and emission characteristics of the flow through a low swirl injector (LSI). An experimental study was carried out on the flame structure, the temperature distribution and the exhaust emission of low swirl pre-mixed combustion under the condition of different swirl number and different fuel composition. In order to qualitatively analyze the flame structure, the velocity distribution of the non-reacting flow through the LSI was measured using the particle image velocimetry (PIV) technique. Experimental results indicated that: (i) the LSI can generate a blue lift-off "W" type flame which consists of four clusters of flames connected together and holds up a long yellow pulsating flame, (ii) the blue flame structure converts the "W" type flame into the "broom" type flame and the distance between the front of the flame and the nozzle shortens with increasing swirl number, (iii) there exist high temperature region flanked by two peaks on the temperature profiles in the blue flame while uniform higher temperature in yellow pulsating flame, (iv) the NOx and CO emission level of the LSI mainly depends on the gas composition and thermal load.
\end{abstract}

Key words: combustion; low swirl injector; emission; swirl number; flame

\section{Introduction}

Lean premixed combustion is becoming an attractive alternative for "state-of-the-art" practical combustion systems because of its very low emissions and very high efficiency. Nevertheless the lean premixed combustion presents a challenge to achieve acceptable flame stability. Swirl is a predominant flame stabilization mechanism found in premixed combustion system. High swirl utilizes recirculation zone to achieve flame stability and reliable combustion, but its turndown can be limited in premixed combustion. The relatively new low-swirl approach has shown great promise in expanding the flame stability and flammable limit of lean premixing combustion [1]. 


\begin{tabular}{|c|c|c|c|}
\hline \multicolumn{4}{|c|}{ Nomenclature } \\
\hline$d$ & $\begin{array}{l}\text { Diameter of hole on perforated plate } \\
{[\mathrm{mm}]}\end{array}$ & $R=r_{2} / r_{1}$ & $\begin{array}{l}\text { Ratio of radii of the center channel } \\
\text { and LSI nozzle [-] }\end{array}$ \\
\hline$L_{c}$ & $\begin{array}{l}\text { Length difference between annular } \\
\text { channel and center channel }[\mathrm{mm}]\end{array}$ & $S$ & Swirl number [-] \\
\hline$L_{i}$ & Swirl recess distance $[\mathrm{mm}]$ & $U_{0}$ & $\begin{array}{l}\text { Bulk flow velocity at inlet of low } \\
\text { swirl injector }[\mathrm{m} / \mathrm{s}]\end{array}$ \\
\hline$L_{s}$ & $\begin{array}{l}\text { Length of top boundary of vane on } \\
\text { axial direction }[\mathrm{mm}]\end{array}$ & $X$ & $X$ Axial Coordinate $[\mathrm{mm}]$ \\
\hline$m$ & $\begin{array}{l}\text { Mass flux ratio through low swirl } \\
\text { injector }\left[\mathrm{kg} \mathrm{s}^{-1} \mathrm{~m}^{-2}\right]\end{array}$ & $Y$ & Axial Coordinate $[\mathrm{mm}]$ \\
\hline$m_{c}$ & $\begin{array}{l}\text { Mass flux through center channel } \\
{\left[\mathrm{kg} \mathrm{s}^{-1} \mathrm{~m}^{-2}\right]}\end{array}$ & $Z$ & Axial Coordinate $[\mathrm{mm}]$ \\
\hline$m_{s}$ & $\begin{array}{l}\text { Mass flux through swirl annulus } \\
\text { channel }\left[\mathrm{kg} \mathrm{s}^{-1} \mathrm{~m}^{-2}\right]\end{array}$ & & Creek symbols \\
\hline$n$ & Number of swirl vanes [-] & $\alpha$ & $\begin{array}{l}\text { Overlapping angle between two } \\
\text { neighboring vanes [deg] }\end{array}$ \\
\hline$P$ & Pressure $[\mathrm{Pa}]$ & $\theta_{0}$ & $\begin{array}{l}\text { Deviation angle at the end of the vane } \\
{\left[{ }^{\circ}\right]}\end{array}$ \\
\hline$r_{1}$ & $\begin{array}{l}\text { Inner radius diameter of the center } \\
\text { channel }[\mathrm{mm}]\end{array}$ & $\varphi$ & $\begin{array}{l}\text { Equivalence ratio of premixed } \\
\text { methane and air }\end{array}$ \\
\hline$r_{2}$ & Inner radius of LSI injector $[\mathrm{mm}]$ & & \\
\hline
\end{tabular}

The development of low-swirl concept originally conceived for laboratory studies on flame and turbulent interactions. Chan et al. [2] found that a divergence flow induced by low swirl could sustain a premixed flame of methane and air in no recirculation flow cases when they studied low swirl combustion (LSC) with tangential injection. Cheng and Yegian [3-5] firstly developed a fixed vane swirler to replace the tangential injection and simplified the complex configuration of a low swirl injector (LSI). Their experimental study demonstrated that the LSI with the vane swirler could produce identical mean velocity profiles and combustion performance similar to the tangential injection. Hereafter, Johnson et al. [6] compared the flow field and emissions of LSC and high swirl combustion (HSC). They found that the flame stability of the LSC was not influenced by the equivalent ratio, the inlet temperature, the pressure and the mass flow rate of the center channel. Under the same condition, the NOx emissions of the LSC were $60 \%$ lower than those of the HSC. Cheng and his group [7-15] performed complete studies on LSC applied to industrial gas turbines. It was concluded that the LSC could sustain ultra-lean premixed combustion without recirculation and its low temperature and short residence time of the reaction flow could control the NOx and CO emissions. In addition, LSC had a self-similar characteristic of flow and were insensitive to the components of the fuel. 
Subsequent to the development of practical application study of LSC, several projects were pursued to adapt LSC to industrial and commercial premixed combustion system. With the support of the U.S.A. Department of Energy (DOE), Yegian and Cheng [16] began to adapt the LSC concept to a small domestic water heater. Maxon Corporation commercialized a low-swirl burner, the M-PAKT burner, with its ultra-low emissions and output capacities ranging from 0.4 to $5.8 \mathrm{MBtu} / \mathrm{hr}$. DOE funded the development of the LSI for use in natural gas-burning turbines for on-site electricity production. Cheng et al. [17] adapted the LSI technology to the Taurus 70 gas turbine that generated about 7 megawatts of electricity. The team successfully converted the current high-swirl combustor of the turbines to operate in the low-swirl mode and reduce the NOx emissions to below $6.7 \mathrm{mg} / \mathrm{m}^{3}$. With the support of the California Energy Commission (CEC), Berkeley Lab also collaborated with Elliot Energy Systems to develop micro turbines with the LSI. The test in an engine showed that the LSI could lower the NOx emissions of the engine to below $5.4 \mathrm{mg} / \mathrm{m}^{3}$. Recently, Berkeley Lab [18] was also developing a gas turbine fitted LSI to operate on pure hydrogen. Their test results showed that the LSI designed for burning hydrogen can accept fuels with over $90 \% \mathrm{H}_{2}$ under the simulated gas turbine conditions.

A wide range of research on LSI has been carried out and many theories have been developed [19-22]. These theories included the blockage ratio of the perforated-screen controls the flow distribution and the turbulent level, the self-similar divergent flow without recirculation founds the flame stabilization mechanism, the premixed flame consumes the reactants in a form of self-sustained reacting waves and the flame propagating speed is controlled by the mixture compositions, the thermodynamic conditions and the turbulence intensity. Based on the brief literature review above, it can be seen that much effort has been made to study the velocity distribution of the flow field and stability of the low swirl flame. It is recognized that the flow, flame topology, temperature distribution and emissions of fuel gas of LSC are coupled with each other. To the best of the authors' knowledge, there is a lack of available experimental data on the flame topology and temperature distribution feature especially for the low swirl injector. To this end, the present research is aimed to experimentally analyze both the flame structure and temperature distribution of the flow through the LSI from a low swirl number to a high swirl number. Besides, the emissions and the pollution production of the flame are also analyzed in more detail. 


\section{Experimental procedures}

\subsection{Experimental apparatus}

The experiments are conducted on the low swirl combustion test rig at Dalian Maritime University, China. The schematic diagram of the experimental apparatus as well as the test section is illustrated in Fig. 1. The LSI is fitted to a flange of the inlet pipe which is vertically mounted on a metal shelf. The swirl vanes and perforated screen of the LSI can be conveniently replaced. The fuel gases used in the current experiment include propane, methane and methane with hydrogen. Both the propane gas and the methane gas have $99.999 \%$ purity. The methane gas with hydrogen contains $70 \%$ methane and $30 \%$ hydrogen. In the current work, experiments were conducted in an open atmospheric environment and in a closed environment, respectively.

The flow of both the fuel gas and the air are measured using flowmeters installed in the fuel gas pipeline and the air pipeline respectively, as shown in Fig.1 (a). Both flowmeters are Yoke LUGB vortex flowmeters with an accuracy of $\pm 1.5 \%$ and they can show the temperature and pressure of the flow at the same time. The fuel gas and air are mixed in the mixer flow through the LSI and are ignited by a pulse igniter. The velocity of the mixed gas is measured using the speed probe with an accuracy of $\pm 0.5 \%$. The speed probe connected to a pressure sensor, Keller Type PD-23, which has an accuracy of $\pm 0.5 \%$ FS. The temperature of the mixed gas is measured using the $\mathrm{Ni}-\mathrm{Cr}-\mathrm{Si} / \mathrm{Ni}-\mathrm{Si}$ (Type-K) thermocouple with an accuracy of $\pm 1.5{ }^{\circ} \mathrm{C}$. The signals of the pressure sensor and thermocouple are gathered and transferred to a computer by a data acquisition. The flame detection system can detect and shut down according to the standard prescribed procedures.

The flame images of the flow through LSI are shot and recorded using a Nikon D5100 camera. The exposure times of the camera are set at $1 / 100 \mathrm{~s}$. The temperature distribution in the flame is measured using a Pt 30\% Rh (Type B) thermocouple. The thermocouple has $0.50 \mathrm{~mm}$ bead diameter, $0.8 \mathrm{~s}$ response time with an accuracy of $\pm 1.5^{\circ} \mathrm{C}$. The signals of the thermocouple are collected and transferred to a computer by the data acquisition system. The thermocouple is fixed in a coordinate frame which has a four coordinate displacement platform and every coordinate displacement is driven by stepping motors. 


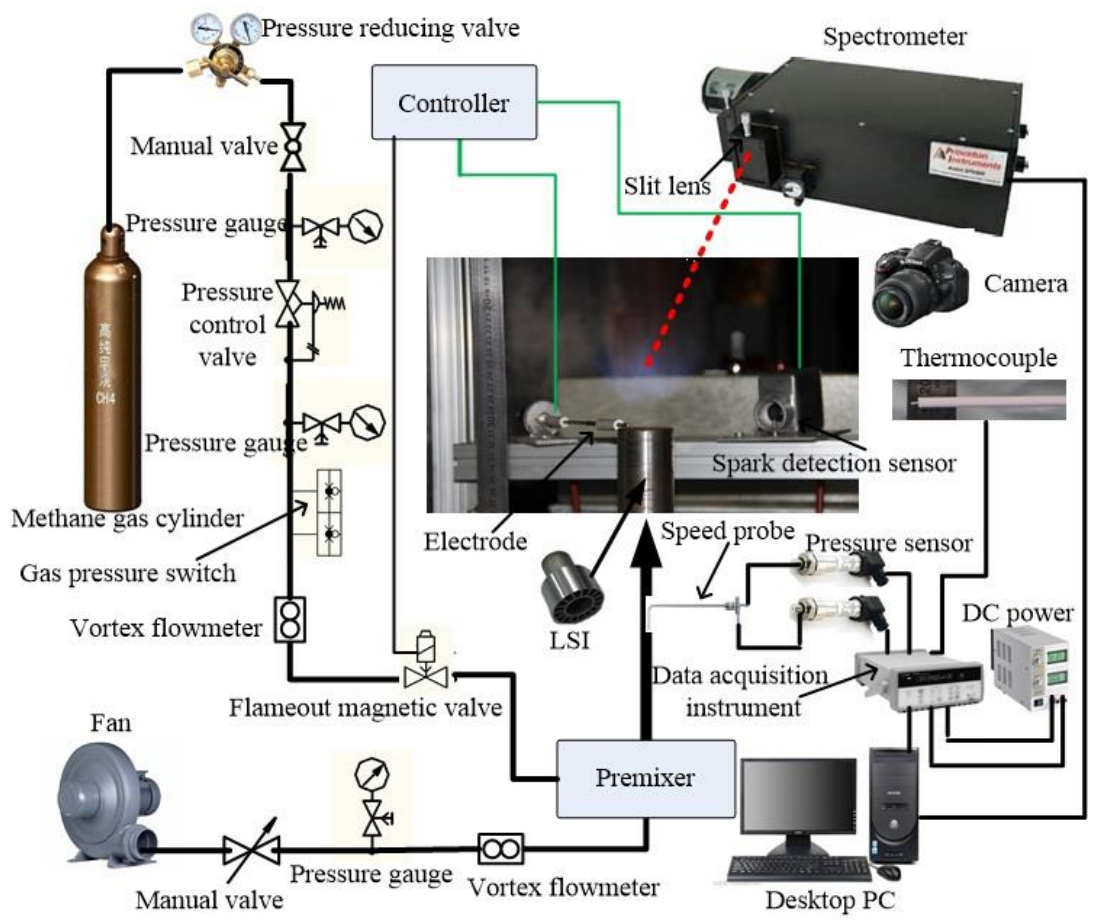

(a)

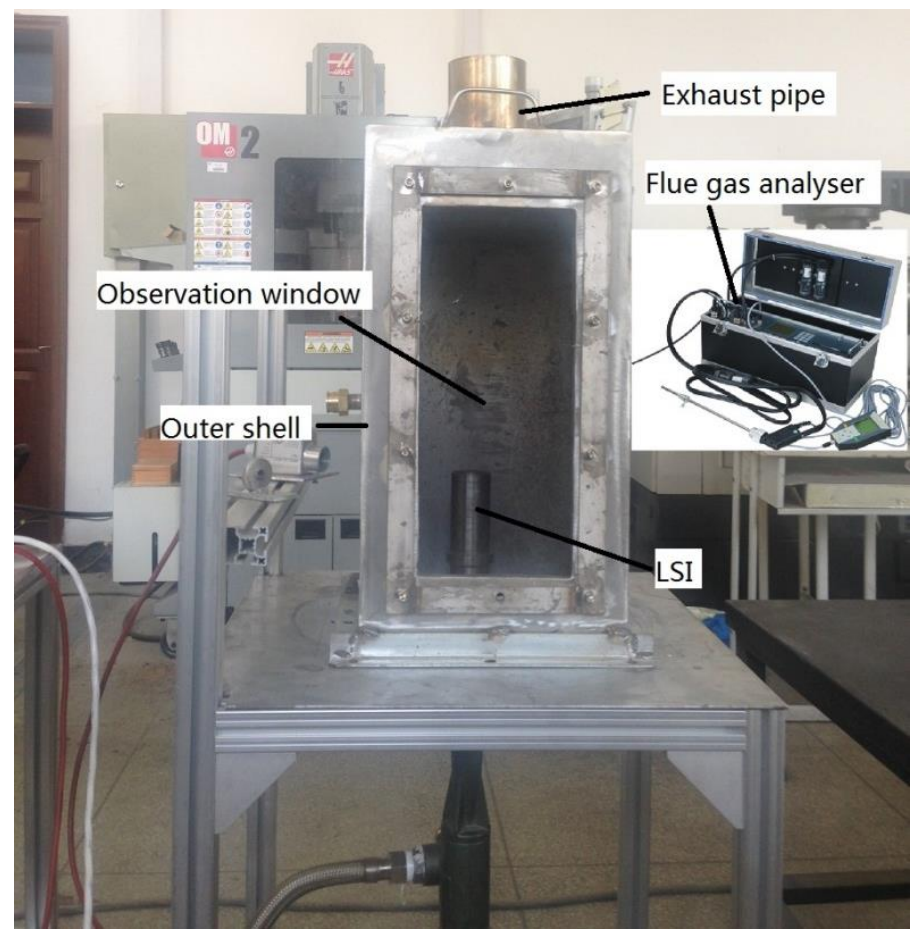

(b)

Fig.1. Schematic diagram of experimental setup: (a) Experiment in an open atmospheric environment,

(b) Experiment in a closed environment 
The spectroscopy measurements of the flame emission are carried out by means of a spectrograph, Acton SP2500 Spectrometer from Princeton Instruments. The spectrograph has $500 \mathrm{~mm}$ focal length, f/6.5 focal ratio, and $1.52 \mathrm{~nm} / \mathrm{mm}$ dispersion with a wavelength accuracy of $\pm 0.2 \mathrm{~nm}$ and repeatability accuracy of $\pm 0.05 \mathrm{~nm}$. The CCD camera of the spectrometer has a resolution of $24 \mu \mathrm{m} \times 24 \mu \mathrm{m}$ pixels.

In the current work, in order to measure the non-reacting flow characteristics and the exhaust emission of LSI, a rectangular outer shell is used to cover the LSI, as demonstrated in Fig. 1(b). The dimension of the outer shell is $300 \mathrm{~mm}(\mathrm{~L}) \times 300 \mathrm{~mm}(\mathrm{~W}) \times 600 \mathrm{~mm}(\mathrm{H})$. An exhaust pipe is mounted on the top of the outer shell. An observation window is set on the front wall of the outer shell with $400 \mathrm{~mm}$ in length and $210 \mathrm{~mm}$ in width.

The experiment on the non-reacting flow characteristics is similar to our previous work [23], for the purpose of completeness, the different boundary condition at inlet is still summarized. An incident window of the laser ray from laser generator is set on the left wall of the outer shell. The velocity vector of the flow through the LSI in the rectangular channel can be captured by a PIV system (TSI, United States) consisting of a double-pulsed Nd:YAG laser (wavelength $532 \mathrm{~nm}$, repetition rate $7.5 \mathrm{~Hz}$ ), and a single frame-straddling CCD camera with a resolution of $2048 \times 2048$ pixels. The optic lens can capture a view field of $284 \times 284 \mathrm{~mm}$ with a resolution of $1200 \times 1000$ pixels. The data analysis of the PIV is performed using the software package "Insight 3G". The tracer particles are hollow-glass beads with a diameter of 8 $\mu \mathrm{m}$. Each experiment can record at least 200 image pairs. Two-dimensional (2D) velocity vectors are obtained to acquire the mean velocity vector $U$ on the span-wise section. Since the ratio of the hydraulic diameter of the rectangular channel to the diameter of the LSI is designed as 7.5:1, the recirculation at the corner of the rectangular channel can be avoided. As a consequence, the velocity distribution of the rectangular channel could be similar to that in an open atmospheric environment, which can be used to qualitatively analyze the flame structure in an open atmospheric environment as demonstrated Yegian, et al. [4].

During the experiment of the measurement of the exhaust emission, the flame structure of the LSI can be observed through the observation window and the GA-21 plus is used to measure the exhaust emission of LSI. The GA-21 plus is a multi-functional flue gas analyzer. The concentration of the gases including 
$\mathrm{O} 2, \mathrm{CO}, \mathrm{NO}, \mathrm{SO}_{2}, \mathrm{H}_{2} \mathrm{~S}$ and $\mathrm{H}_{2}$ can be measured directly using the electrochemical cells. The remaining components can thus be calculated. The concentrations of $\mathrm{O}_{2}$ and $\mathrm{CO}_{2}$ are shown in percentage. The concentrations of the remaining gases are shown as follows: volume concentration in ppm, absolute mass concentration in $\mathrm{mg} / \mathrm{m}^{3}$, mass concentration relative to the oxygen content in $\mathrm{mg} / \mathrm{m}^{3}$. In addition, the air inlet, ambient temperature and flue gas temperature can be measured. The resolution of each sensor is $0.01 \%$ FS with an accuracy of $\pm 0.05 \%$ FS.

\subsection{Configuration of LSI}

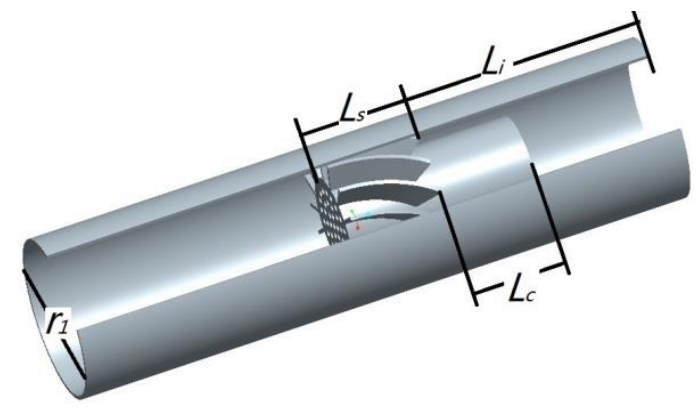

(a)

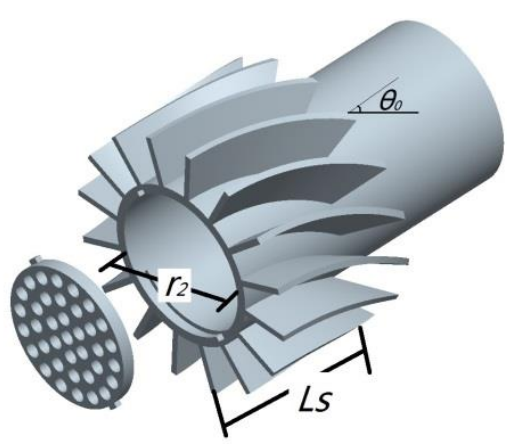

(b)

Fig. 2. Schematic diagram of low swirl injector (LSI): (a) Low swirl injector, (b) Swirl vanes and perforated screen

The configuration of the low swirl injector (LSI) is consistent to that of our previous work [23]. The LSI consists of an annular channel with swirl vanes and a center channel covered with a perforated screen, as is illustrated in Fig. 2. The vanes are designed as a curved surface in order to reduce the flow resistance. The flow through the LSI is divided into two parts: an annular swirled flow and a center straight flow. The annular swirled flow interacts with the center straight flow in the end of the injection tube and produces a low swirl flow. The curved surface is shaped according to the method provided by Yang et al. [24]. The parameters of the LSI are listed in Table 1. The blockage ratio of the center straight flow is varied by changing the diameter of the hole in the perforated screen, and, therefore, the ratio of the annular flow and the straight flow is regulated. As a result, the swirl number and the flow field structure of the flow through the LSI will be controlled. 
Table 2 lists the parameters of LSIs for different vane angles of $\theta_{0}=37^{\circ}, \theta_{0}=42^{\circ}$ and $\theta_{0}=50^{\circ}$. In Table 2, $d$ is the diameter of hole on perforated plate, $m=m_{c} / m_{s}$ is the ratio of the mass flows of the annular channel flow $m_{c}$ to the straight flow $m_{s}$, and $S$ is the swirl number of the flow through LSI.

Table 1 Geometric dimensions of LSI.

\begin{tabular}{cc}
\hline Parameters & Value \\
\hline$r_{1}$ & $20 \mathrm{~mm}$ \\
$r_{2}$ & $12.5 \mathrm{~mm}$ \\
$\theta_{0}$ & $37^{\circ} / 42^{\circ} / 50^{\circ}$ \\
$n$ & 16 \\
$L_{i}$ & $58.5 \mathrm{~mm}$ \\
$L_{\mathrm{S}}$ & $24.25 \mathrm{~mm}$ \\
$L_{\mathrm{C}}$ & $25.75 \mathrm{~mm}$ \\
$R$ & 0.625 \\
\hline
\end{tabular}

Table 2 The values of LSIs in the experiments.

\begin{tabular}{cccc}
\hline$\theta_{0}$ & $d / m m$ & $m$ & $S$ \\
\hline $37^{\circ}$ & 0 & 0 & 0.623 \\
$37^{\circ}$ & 1.883 & 0.198 & 0.587 \\
$37^{\circ}$ & 2 & 0.232 & 0.575 \\
$37^{\circ}$ & 2.225 & 0.303 & 0.545 \\
$37^{\circ}$ & 2.373 & 0.355 & 0.521 \\
$42^{\circ}$ & 2.904 & 0.568 & 0.414 \\
$42^{\circ}$ & 1.883 & 0.223 & 0.691 \\
$42^{\circ}$ & 2 & 0.257 & 0.675 \\
$42^{\circ}$ & 2.225 & 0.339 & 0.631 \\
$42^{\circ}$ & 2.373 & 0.397 & 0.598 \\
$42^{\circ}$ & 2.904 & 0.626 & 0.462 \\
$50^{\circ}$ & 2.225 & 0.423 & 0.770 \\
$50^{\circ}$ & 2.373 & 0.494 & 0.713 \\
$50^{\circ}$ & 2.904 & 0.778 & 0.507 \\
\hline
\end{tabular}

\section{Results and discussion}

\subsection{Distribution of velocity vector}

Fig. 3 shows the 2D mean velocity vector along span-wise section of the non-reacting flow captured by the LSI at different swirl number $(S)$ of $0.521,0.575$ and 0.623 respectively for fixed $\theta_{0}=37^{\circ}$. Fig. 3(a) presents the contour velocity vector for the case of $S=0.521$ in the near field $(\mathrm{Z}<25 \mathrm{~mm})$, a higher $U$ center region is produced by the straight flow through the center channel around the axis is surrounded by a lower 
$U$ swirling flow supplied by the swirl annular channel. The annular swirling flow spreads outward, which generates an adverse pressure gradient and further induces the central straight flow decelerate and divergence along the axis. In the far field $(X>25 \mathrm{~mm})$, a lower $U$ center region flanked by two velocity peaks around the axis is produced.

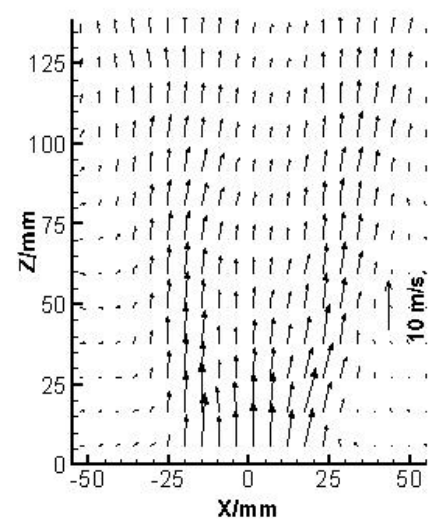

(a)

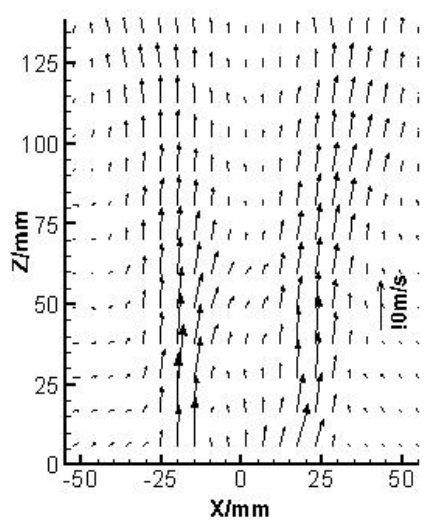

(b)

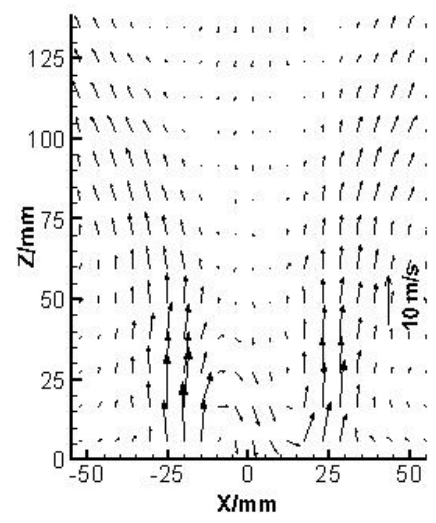

(c)

Fig. 3. 2D mean velocity vector on span-wise section. (a) $S=0.521$; (b) $S=0.575$; (c) $S=0.623$.

With increasing $S$ the whole divergent flow structure shifts upstream into the LSI. When $S=0.575$, the disturbance of a lower $U$ center region flanked by two velocity peaks around the axis is generated in the near field $(\mathrm{Z}<25 \mathrm{~mm})$. When $\mathrm{S}=0.623$, no flow comes through the central channel, then the flow field has a central recirculation and the stagnation point stays inside the LSI. As discussed in previously published works $[6,10,11,19]$, the heat release can enhance the flow recirculation at the far field but have little impact on the flame stabilization mechanism in a certain range of heat load. Therefore, $2 \mathrm{D}$ velocity distribution of the cold flow through LSI can qualitatively explain the flow field characteristics during the combustion process.

\subsection{Flame structure}

Figure 4 depicts the images of the flame structure generated by the LSIs as the equivalence ratio of the premixed propane and air is $\varphi=0.84$, the bulk flow velocity at inlet is $U_{0}=10 \mathrm{~m} / \mathrm{s}$ and the vane angle is $\theta_{0}=37^{\circ}$ corresponding to the velocity distribution of the non-reacting flow shown in Fig. 3. 
The LSI generates a blue lift-off "W" type of cold flame which holds up a long yellow pulsating flame for the case of $S=0.521$, as shown in Fig. 4 (a). For lean pre-mixed combustion, the flame front stagnates at the position where the flame propagating speed is equal to the local flow velocity. As such, the blue "W" type of the flame consists of four clusters of blue flames separated at the bottom but connected together at the top along circumferential direction is produced. This could be explained by the fact that the effect of the higher $U$ center region in the near field according to Fig. 3(a). For the case of $S=0.575$, the flame structure converts the "W" type flame into the "broom" type flame, as illustrated in Fig. 4(b). This could be attributed to that the velocity distribution of a lower $U$ center region flanked by two velocity peaks in terms of Fig. 3. It should be noted that, when $S=0.623$, the LSI generates the diffusion type flame attached to the nozzle in Fig. 4(c). This result may be attributed to the central recirculation stays inside the LSI according to Fig. 3(c).

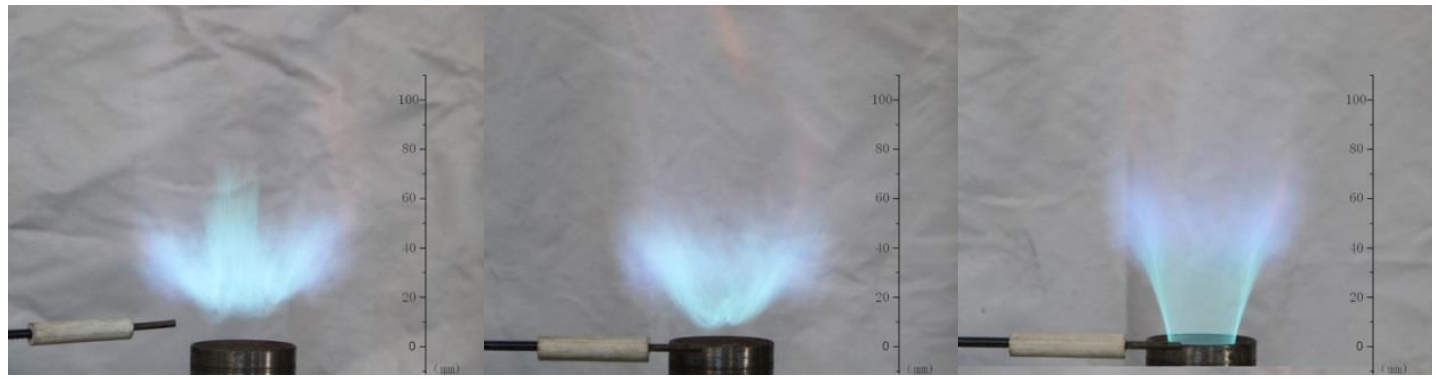

(a)

(b)

(c)

Fig. 4. Flame structure at different swirl number when $\theta_{0}=37^{\circ}\left(\mathrm{C}_{3} \mathrm{H}_{8}\right)$ : (a) $\mathrm{S}=0.521$, (b) $\mathrm{S}=0.575$, and (c) $S=0.623$.

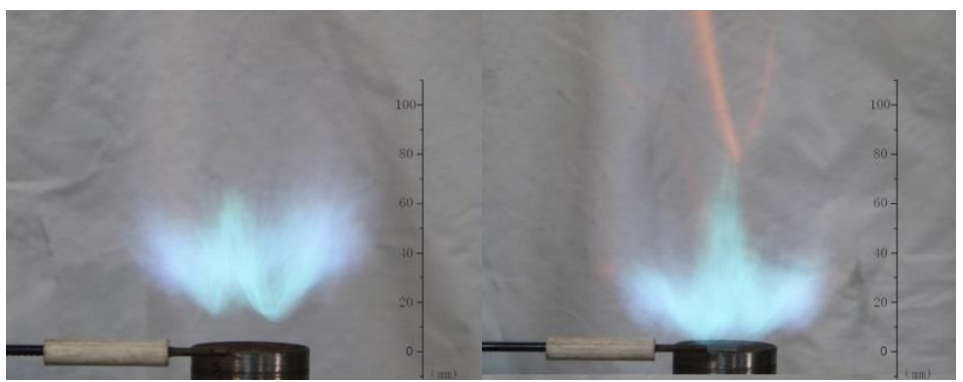

(a)

(b)

Fig. 5. Flame structure $\left(\mathrm{C}_{3} \mathrm{H}_{8}\right)$ : (a) $S=0.598$ and $\theta_{0}=42^{\circ}$, (b) $S=0.713$ and $\theta_{0}=50^{\circ}$. 
Fig. 5 presents the flame structure generated by the LSIs when $\varphi=0.84\left(\mathrm{C}_{3} \mathrm{H}_{8}\right), U_{0}=10 \mathrm{~m} / \mathrm{s}, \theta_{0}=42^{\circ}$ and $\theta_{0}=50^{\circ}$. It can be seen clearly from Fig. 5(a) that the structure of the flame clusters separates at the bottom of the flame when $S=0.598$ and $\theta_{0}=42^{\circ}$. Since the action of the straight flow through the center channel, LSI still generates lift flame for the case of high swirl flow when $S=0.713$ and $\theta_{0}=50^{\circ}$, as seen in Fig. 5(b).

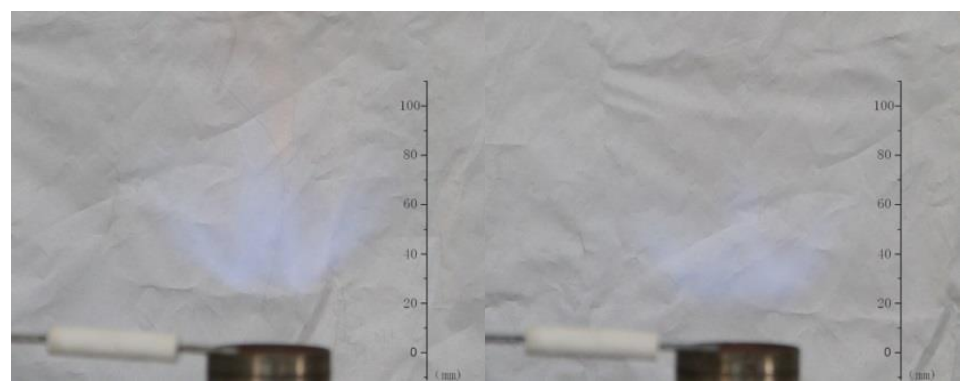

(a)

(b)

Fig. 6. Flame structure of different fuel gas as $\theta_{0}=37^{\circ}$ and $S=0.521$. (a) $\mathrm{CH}_{4}$; (b) $70 \% \mathrm{CH}_{4}+30 \% \mathrm{H}_{2}$.

Fig. 6 indicates the flame structure under the operating conditions of $U_{0}=10 \mathrm{~m} / \mathrm{s}$ and $\theta_{0}=37^{\circ}$ at $\varphi=0.58$ $\left(\mathrm{CH}_{4}\right)$ and $\varphi=0.51\left(70 \% \mathrm{CH}_{4}+30 \% \mathrm{H}_{2}\right)$ respectively. The topology structure of the flame for the different fuels in Fig. 6 is almost identical to that in Fig. 4(a). It is noted that the "blue" flame becomes weak using methane in Fig. 6(a), this could be explained by the fact that the reduction of the carbon content in fuel gas comparing to that in Fig. 4(a). For the case of methane gas with hydrogen, the "blue" flame becomes weak which is almost invisible to the naked eye, as shown in Fig. 6(b). This is due to the fact that further reduction of the carbon content in fuel gas.

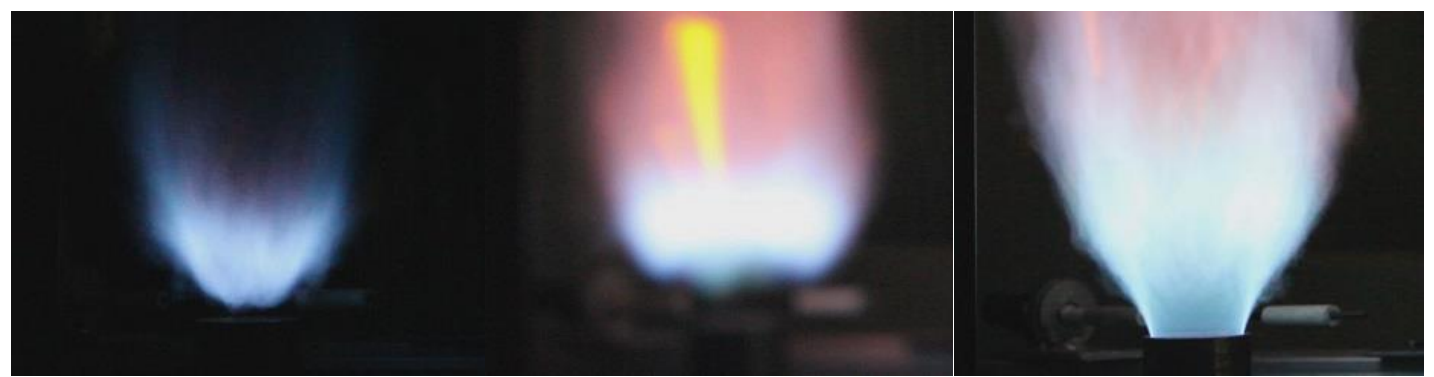

(a)

(b)

(c)

Fig. 7. Flame structure of different equivalence ratio using $70 \% \mathrm{CH}_{4}+30 \% \mathrm{H}_{2}$ as $\theta_{0}=37^{\circ}$ and $S=0.575$. (a)

$$
\varphi=0.50 \text {, (b) } \varphi=0.75 \text {, and (c) } \varphi=0.85 \text {. }
$$


Figure 7 shows the change of the flame structure with the equivalence ratio increasing from $\varphi=0.50$ $\left(70 \% \mathrm{CH}_{4}+30 \% \mathrm{H}_{2}\right)$ to $\varphi=0.85$ under the operating conditions of $U_{0}=10 \mathrm{~m} / \mathrm{s}, \theta_{0}=37^{\circ}$ and $S=0.575$. As for lean pre-mixed combustion, the turbulent flame speed increases with the increase of both the equivalence ratio and the turbulence intensity in the flow field. In the current experiment, the uneven uniformity of the premixing gas increases with the increase of the equivalence ratio because of the premixer with limited premixing performance. The uneven uniformity of the premixing gas in the flow field can stimulate the fluctuation of the heat release rate and then leads to stronger turbulent intensity and flame fluctuation. In this case, the turbulent flame speed will increase with the increase of the equivalence ratio of the premixed gas at the inlet, and this can lead to the flame fluctuation and further result in the incomplete combustion. In addition, it is observed that the axial velocity in the center region of the flow through the LSI decays linearly, as shown in Fig. 3 (b). A lifted flame is generated when $\varphi=0.50$, as shown in Fig. 6(a). The distance between the flame bottom and the exits shortens due to the higher flame speed with increasing equivalence ratio. And the blue flame length shortens and yellow pulsating flame becomes visible because of the incomplete combustion with increasing equivalence ratio. An unstable lifted flame is generated when $\varphi=0.75$ and will turn into attached flame if there exists disturbance as shown in Fig. 6(b). This is because the flame fluctuation is produced with the increase of the equivalence ratio. A stable attached flame is generated when $\varphi=0.85$ under the effects of the boundary layer of LSI, as demonstrated in Fig. 7(c). This demonstrates that the flame topology structure can be changed by changing the equivalence ratio of the pre-mixed gas under certain conditions.

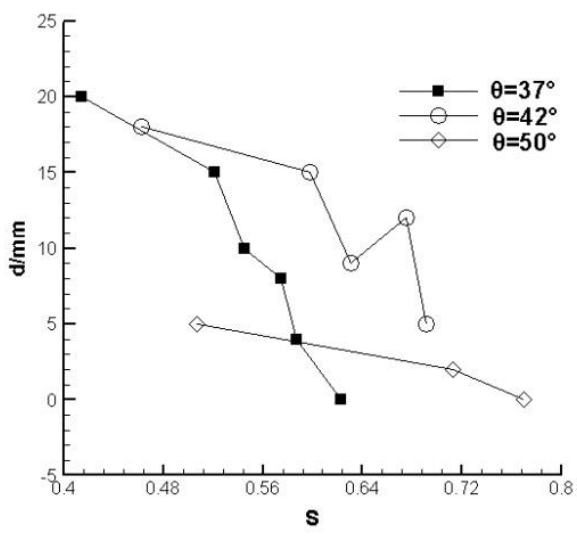

Fig. 8. Variation of position of the flame bottom with swirl number. 
Figure 8 shows the change of the distance from the exit of LSI to the flame bottom with swirl number at three different $\theta_{0}=37^{\circ}, 42^{\circ}$ and $50^{\circ}$ for fixed $\varphi=0.84\left(\mathrm{C}_{3} \mathrm{H}_{8}\right)$ and $U_{0}=10 \mathrm{~m} / \mathrm{s}$. The distance between the flame bottom and the exits shortens with the increase of $S$. This implies that the whole feature velocity vector field generated by LSI shifts into the exit of the LSI as the swirl number increases for $\theta_{0}=37^{\circ}$, $\theta_{0}=42^{\circ}$ and $\theta_{0}=50^{\circ}$, this is consistent with previous results reported by Cheng [3].

\subsection{Temperature distribution of the flame}

In the current experiment, the measuring temperature needs to be modified in order to improve the accuracy of the measurement, and the method of the modification can be found in Appendix A in more detail.

Fig. 9 shows the temperature distribution of flame at three different swirl numbers of $0.521,0.575$, and 0.623. This is corresponding to the flame structure shown in Fig. 4. The center of the flame is located at $X=0 \mathrm{~mm}$, while the nozzle of the LSI is located at $Z=0 \mathrm{~mm}$. The measurement points of the temperature are arranged at a distance of $Z=5 \mathrm{~mm}$ from the nozzle, the flame front, the interface between the "blue" flame and "yellow" flame and a distance of $20 \mathrm{~mm}$ from the interface, respectively.

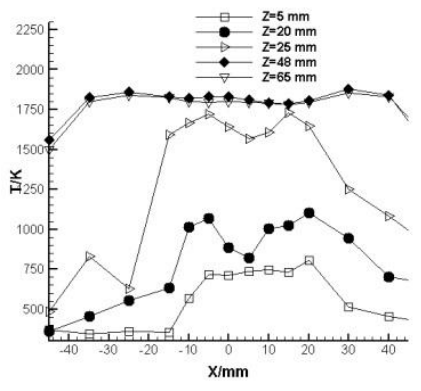

(a)

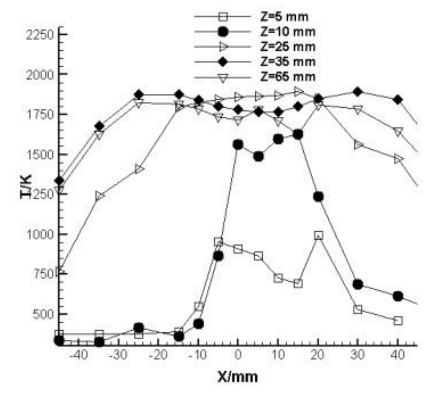

(b)

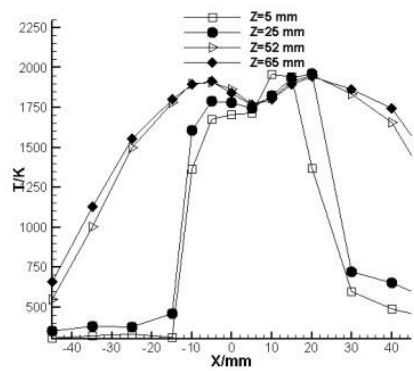

(c)

Fig. 9. Temperature distribution of flames as $\theta_{0}=37^{\circ}\left(\mathrm{C}_{3} \mathrm{H}_{8}\right)$ : (a) $S=0.521$, (b) $S=0.575$, and (c) $S=0.623$.

At $Z=5 \mathrm{~mm}$, the measurement points are between the flame bottom and the injector, it is noted that the peak temperature appears in the central area around the axis $(-10 \mathrm{~mm} \leqslant X \leqslant 20 \mathrm{~mm})$ illustrated in Fig. 9 (a). At $Z=20 \mathrm{~mm}$ and $Z=25 \mathrm{~mm}$, there exist high temperature central area around the axis $(-25 \mathrm{~mm}<\mathrm{X}<25 \mathrm{~mm})$, which is flanked by two peaks on the temperature profiles in the flame and corresponds to the flame structure with four clusters of the blue flames separated on the bottom along circumferential direction. At 
$Z=48 \mathrm{~mm}$ and $Z=65 \mathrm{~mm}$, they are separately located at the interface and in yellow pulsating flame, which shows a uniform higher temperature region around the axis $(-35 \mathrm{~mm}<\mathrm{X}<35 \mathrm{~mm})$.

As shown in Fig. 9(a) and (b), the temperature distribution is consistent with the change of the flame structure from the "W" type to the "broom" type presented in Fig. 4(a) and (b). It should also be noted that the flame length shortens and the flame zone narrows at the bottom of the flame. As a result, the high temperature zone becomes narrow and the temperature gradients become steeper on both sides of the temperature profile in the blue flame when $S=0.575$ compared with that of $S=0.521$ exhibited in Fig. 9(b). As can be seen in Fig. 9(c), the temperature gradients on both sides become steeper for each temperature profile as $S=0.623$ compared with those of $S=0.521$ and $S=0.575$ shown in Fig. 9(a) and (b).

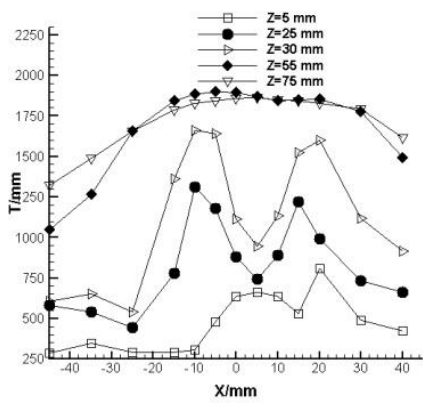

(a)

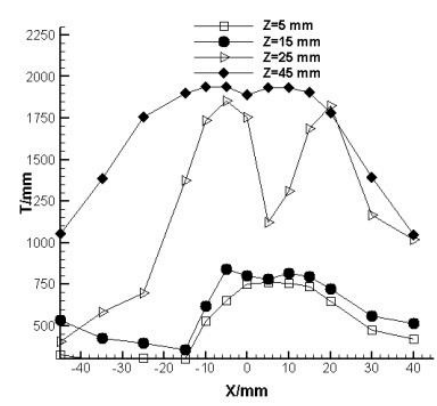

(b)

Fig. 10. Temperature distribution of flames for different fuel gas as $\theta_{0}=37^{\circ}$ and $\mathrm{S}=0.521$ : (a) $\mathrm{CH}_{4}$, (b) $70 \%$

$$
\mathrm{CH}_{4}+30 \% \mathrm{H}_{2} \text {. }
$$

Fig. 10 shows the temperature distribution corresponding to the flame structure illustrated in Fig. 5. The structure of the temperature distribution in the flames for different fuels is almost identical with that in Fig. 10 and Fig. 9(a). Comparing Fig. 9(b) with Fig. 9(a), the whole temperature level in Fig. 9(b) decreases since the fuel gas of $\varphi=0.58\left(\mathrm{CH}_{4}\right)$ has higher combustion heat value than the fuel gas of $\varphi=0.51\left(70 \% \mathrm{CH}_{4}+\right.$ $\left.30 \% \mathrm{H}_{2}.\right)$

Figure 11(a) shows temperature profile along axis at $\theta=37^{\circ}$ and $S=0.521$ corresponding to the flame structure burning $\mathrm{C}_{3} \mathrm{H}_{8}$ presented in Fig. 4(a). Since the lean premixed propane and air can start with slow exothermic reaction at $473 \mathrm{~K}$, the flow through LSI starts to react and releases the heat within $Z \leqslant 15 \mathrm{~mm}$, as shown in Fig. 11(a). The jet fluid of LSI entrains ambient cold air into the reacting flow according to the 
velocity distribution presented in Fig. 3(a), and the reacting flow transfer heat to the cold air within $Z \leqslant 15$ $\mathrm{mm}$. Thus, the temperature increases initially and then decreases slightly at $\mathrm{Z} \leq 15 \mathrm{~mm}$ illustrated in Fig. 11(a). Since the ignition temperature of the propane and air is around $743 \mathrm{~K}$ and it is located at $\mathrm{Z}=15 \mathrm{~mm}$ on the temperature profile, the temperature increases rapidly as $Z \geq 15 \mathrm{~mm}$, and the maximum temperature is reached at the interface between the "blue" flame and "yellow" flame $(Z=48 \mathrm{~mm})$, afterwards, the temperature decreases slowly.

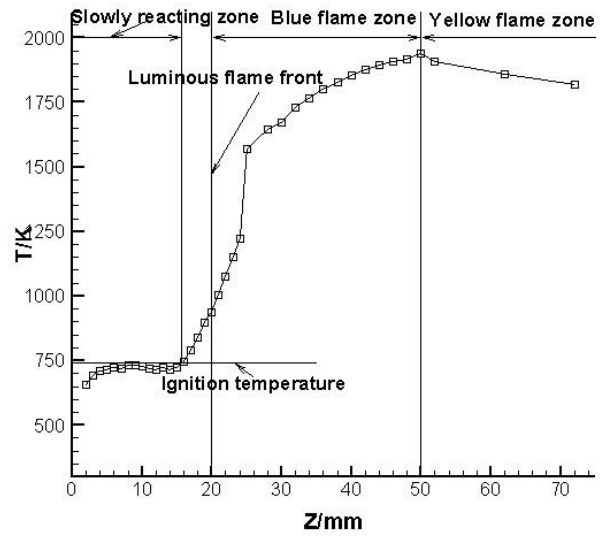

(a)

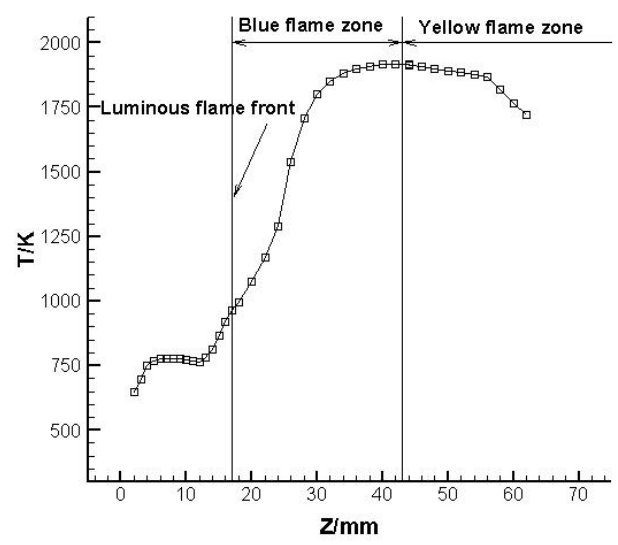

(b)

Fig. 11. Temperature profile along axis as $\theta_{0}=37^{\circ}$ and $S=0.521$ : (a) $\mathrm{C}_{3} \mathrm{H}_{8}$, (b) $70 \% \mathrm{CH}_{4}+30 \% \mathrm{H}_{2}$.

Fig. 11(b) shows temperature profile along axis at $\theta=37^{\circ}$ and $S=0.521$, which corresponding to the flame structure burning $70 \% \mathrm{CH}_{4}+30 \% \mathrm{H}_{2}$ shown in Fig. 6(b). The structure of the temperature distribution along axis for the different fuels is almost identical when comparing Fig. 11(b) with Fig. 11(a).

\subsection{Spectrum analysis}

Fig. 12 shows the spectroscopic at the same flame location for two kinds of fuel gas under the operating conditions of $U_{0}=11.6 \mathrm{~m} / \mathrm{s}, S=0.575$ and $\theta_{0}=37^{\circ}$. The fuel gas is the methane $\left(\mathrm{CH}_{4}\right)$ and the equivalence ratio of the premixed methane and air is $\varphi=0.68$ shown in Fig. 12(a), the test point is located at a distance of $60 \mathrm{~mm}$ from the nozzle and is inside the yellow pulsating flame. As for the fuel gas is methane with hydrogen $\left(70 \% \mathrm{CH}_{4}+30 \% \mathrm{H}_{2}\right)$ and the equivalence ratio is $\varphi=0.53$ shown in Fig. 12(b), the test point is located at a distance of $40 \mathrm{~mm}$ from the nozzle and is also inside the yellow pulsating flame. The spectroscopic of the flame shows that the $\mathrm{C}_{2}^{*}, \mathrm{CH}^{*}$ and $\mathrm{OH}^{*}$ emission in the flame region of the premixed 
methane and air is presented in Fig. 12(a). This demonstrated that the yellow flames are emitted by diatomic carbon, $\mathrm{C}_{2}^{*}$, which are generated by the premixing partial combustion of the fuel since the effect of the flow through the central channel is similar to the inner cone of the Bunsen Flame, as reported by Gaydon $[25,26]$. The spectroscopic of the flame shows that the $\mathrm{CH}^{*}$ and $\mathrm{OH}^{*}$ emission in the flame region of the premixed methane and air, as depicted in Fig. 12(b). The $\mathrm{CH}^{*}$ peak of the methane with hydrogen $\left(70 \% \mathrm{CH}_{4}+30 \% \mathrm{H}_{2}\right)$ is not apparent compared with that of the methane shown in Fig. 12(a).

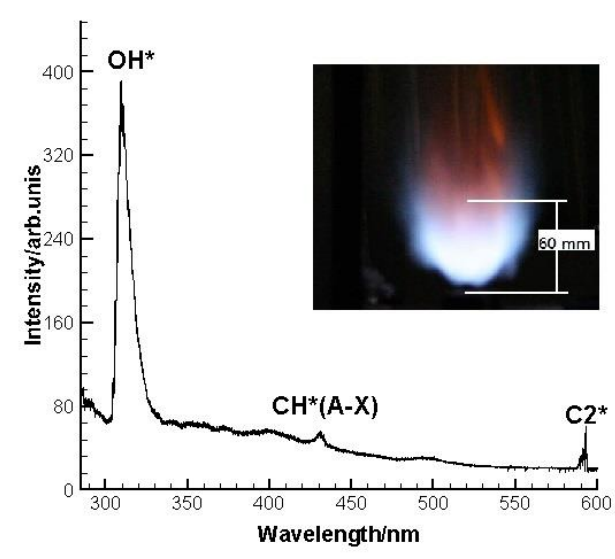

(a)

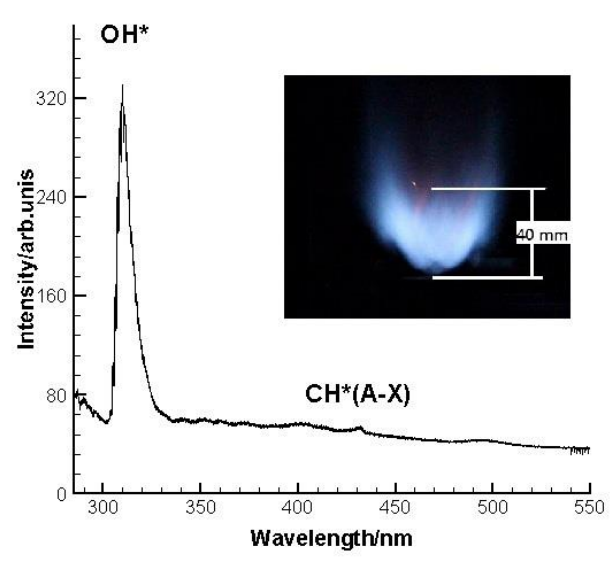

(b)

Fig. 12. Spectroscopic of the flame at $S=0.575$ as $\theta_{0}=37^{\circ}$ : (a) $\mathrm{CH}_{4}$, (b) $70 \% \mathrm{CH}_{4}+30 \% \mathrm{H}_{2}$.

\subsection{Pollutant emission index}

Fig. 13 shows the flame structure generated by the LSI in the rectangular outer shell under the operating conditions of $\varphi=0.84\left(\mathrm{C}_{3} \mathrm{H}_{8}\right), U_{0}=10 \mathrm{~m} / \mathrm{s}$ and $\theta_{0}=37^{\circ}$. The flame structure is almost identical comparing Fig. 13 with Fig. 4(a). This indicates that the lean pre-mixed combustion of LSC has almost same combustion feature both in an open atmospheric environment and in a closed environment.

In the current experiment, the flue gas analyzer is used to measure the emission of the combustion of different components of the fuel. In order to compare the pollution emission under different conditions, the experiment data is processed into pollutant emission index. $E I_{N O}$ is the emission index of $N O$ and can be calculated according to Eq. (1) as below

$$
E I_{N O}=\frac{1000 X_{N O} O}{X_{C O_{2}}} \times \frac{W_{N O}}{W_{1}}(g / K g)
$$


where $X_{N O}$ and $X_{C O 2}$ are the volume fraction of $N O$ and $\mathrm{CO}_{2}$, respectively. $W_{1}$ and $W_{N O}$ are the molecular weight of fuel and NO, respectively.

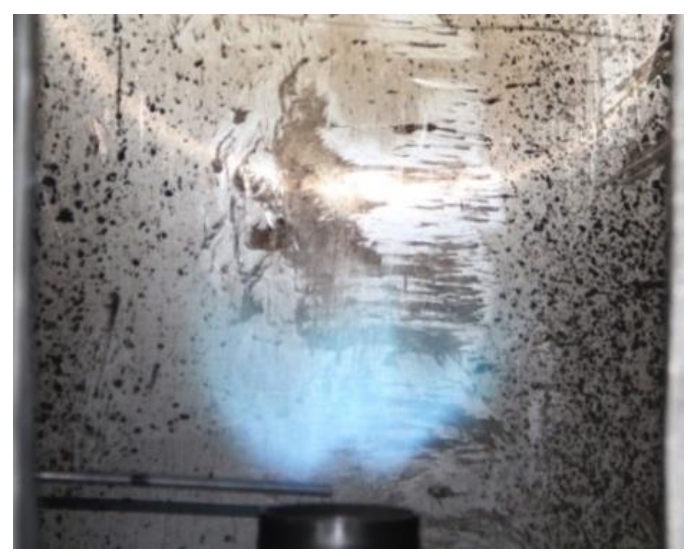

Fig. 13. Image of flame structure as $\theta_{0}=37^{\circ}$ and $\mathrm{S}=0.521\left(\mathrm{C}_{3} \mathrm{H}_{8}\right)$.

The pollutant emission indexes under different conditions are listed in Table 3.

Table 3. Pollutant emission indexes.

\begin{tabular}{cccc}
\hline Components of fuel gas & $S$ & $E I_{N O x}(g / K g)$ & $E I_{C O}(g / K g)$ \\
\hline & 0.521 & 2.37 & 0.53 \\
$\mathrm{C}_{3} \mathrm{H}_{8}$ & 0.575 & 3.29 & 3.3 \\
& 0.623 & 3.30 & 3.3 \\
\hline $\mathrm{CH}_{4}$ & 0.521 & 8.17 & 16.00 \\
\hline $70 \% \mathrm{CH}_{4}+30 \% \mathrm{H}_{2}$ & 0.521 & 0.18 & 0 \\
\hline
\end{tabular}

The $\mathrm{NO}_{\mathrm{x}}$ of the pre-mixed combustion is mainly the thermal $\mathrm{NO}_{\mathrm{x}}$. Thermal $\mathrm{NO}_{\mathrm{x}}$ formation depends on various impact factors, such as the temperature in flame, the degree of temperature uniformity, the blending mode of pre-mixed gas, the residence time of flue gas in high temperature zone, and the equivalence ratio of premixed gas. The $\mathrm{CO}$ of the pre-mixed combustion is formed from the incomplete oxidation of the premixed fuel gas. CO formation depends on the blending mode of the pre-mixed gas and the residence time of the flue gas in combustion zone.

The emissions of the propane in Table 3 are corresponding to the flame structure shown in Fig. 4 and the temperature distribution of the flames illustrated in Fig. 9. The combustion has the same thermal load, 
the flame zone contract, and the high temperature aggregate with increasing swirl number from $S=0.521$ to $S=0.623$ for the propane $\left(\mathrm{C}_{3} \mathrm{H}_{8}\right)$. Therefore, both $E I_{N O x}$ and $E I_{C O}$ increase with the increase of the swirl number from $S=0.521$ to $S=0.623$.

The emissions of methane in Table 3 are corresponding to the flame structure shown in Fig. 6(a) and the temperature distribution of flames illustrated in Fig. 10(a). Since the higher pressure of the exhaust pipe from the methane gas cylinders in the present experiment, the methane mixing with air is not easy to be uniform. As a result, there is more $E I_{N O x}$ and $E I_{C O}$ for methane gas. The emissions of the methane gas with hydrogen in Table 3 are corresponding to the flame structure shown in Fig. 6(b) and the temperature distribution of flames illustrated in Fig. 10(b). The thermal load of the combustion of the methane gas with hydrogen $\left(\mathrm{CH}_{4}\right.$ and $\left.70 \% \mathrm{CH}_{4}+30 \% \mathrm{H}_{2}\right)$ decreases and whole temperature level reduces. As such, $E I_{N O x}$ decreases comparing with that of the propane and the methane. The premixed gas adding hydrogen has lower ignition temperature and the $E I_{C O}$ also decreases. This demonstrates that the gas composition and thermal load have more influence on the emissions of $\mathrm{NO}_{\mathrm{x}}$ and $\mathrm{CO}$ than that of the swirl number for LSI.

\section{Conclusions}

An experimental study was carried out on the combustion and emission characteristics of the flow through a low swirl injector (LSI). The swirl vane angles were respectively $37^{\circ}, 42^{\circ}$ and $50^{\circ}$. The fuel gases used in the experiment include propane, methane and methane with hydrogen. Under the conditions of different swirl numbers and different composition fuel, the flame images were shot, the temperature distributions of the flow were recorded, the spectroscopic of the flame and the emission of the combustion was measured. Manjor findings based on the experimental results were as follows:

(1) The lean premixed fuel and air flow through the LSI can sustain steady combustion at a lower swirl number.

(2) The LSIs can generate a blue lift-off "W" type flame holding up surrounding a long yellow pulsating flame and the blue flame consists of four clusters of flames connected together. The blue flame structure converts the "W" type flame into the "broom" type flame and the distance between the front of the flame and the nozzle shortens with increasing swirl number. 
(3) There are high temperature region flanked by two peaks on the temperature profiles in the blue flame and uniform higher temperature in yellow pulsating flame corresponding to the flame structure of LSC. The high temperature zone narrows and the temperature gradients become steeper on both sides of the temperature profile in blue flame with the increase of the swirl number.

(4) The spectroscopic of the flame shows the yellow flames are emitted by diatomic carbon. The $\mathrm{NO}_{\mathrm{x}}$ and CO emissions level of LSI mainly depend on the gas composition and thermal load.

\section{Acknowledgments}

The author wishes to acknowledge the support of Coal Joint Fund of the National Natural Science Fund Committee of China - Shenhua Group Corporation Ltd. (NSFC Grant Nos. U1361111).

\section{Appendix}

\section{A. Modification of temperature measurement}

For the temperature measurement, the radiative heat loss of the thermocouple will lead to lower temperature than the actual temperature at the measuring point. In order to improve the accuracy of the measurement, the measuring temperature needs to be modified according to the heat balance, as expressed in Eq. (A.1).

$$
T_{f}=T+\frac{\varepsilon \sigma}{h}\left(T^{4}-T_{w}^{4}\right)
$$

where $T_{f}, T$ and $T_{w}$ represent the actual temperature, the measuring temperature and the ambient temperature respectively, as shown in Fig. A.1. Here $\varepsilon$ is the radiation emissivity of the thermocouple, in the current experiment, $\varepsilon=0.22$. $\sigma$ is Stefan-Boltzman constant, $\sigma=5.67 \times 10^{-10} \mathrm{~W} / \mathrm{m}^{2} \cdot \mathrm{K}^{4} . h$ is the convective heat transfer coefficient of the surface of the thermocouple, which can be calculated by:

$$
N u=\frac{h d_{c}}{\lambda}=2+0.6 \operatorname{Re}^{0.5} \operatorname{Pr}^{0.33}
$$

where $\lambda$ is the thermal conductivity of the flue gas. $d_{c}$ is the diameter of the thermocouple probe, $\mathrm{d}_{\mathrm{c}}=0.5 \mathrm{~mm}$. Reynolds number is defined as: 


$$
R e=\frac{u_{\infty} d_{c}}{v}
$$

(A.3)

where $u_{\infty}, v$ and $\operatorname{Pr}$ are the flow velocity, the kinematic viscosity coefficient and Prandtl number of the flue gas, respectively. According to Eq. (A.1), the temperature calibration curve can be obtained and is illustrated in Fig. A.1.

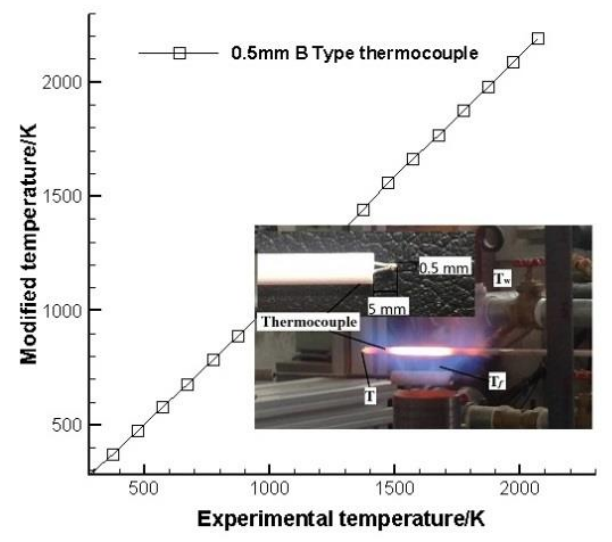

Fig. A.1 Temperature calibration curve.

\section{References}

[1] R.K. Cheng, H. Levinsky. Chapter 6 - lean premixed burners. In: Dunn-Rankin, D. (ed.) Lean

Combustion technology and control, pp. 161-177. Academic, Burlington (2008).

[2] C.K. Chan, K.S. Lau, W.K. Chin, R.K. Cheng. Freely propagating open premixed turbulent flames stabilized by swirl. Proceedings of 24th International Symposium on Combustion. Pittsburgh, American, 511- 518 (1992).

[3] R.K. Cheng. Velocity and scalar characteristics of premixed turbulent flames stabilized by weak swirl. Combust. Flame 101 (1995) 1-14.

[4] D.T. Yegian, R. K. Cheng. Development of a lean premixed low-swirl burner for low NOx practical applications. Combust. Sci. Technol. 139 (1998) 207-227.

[5] R.K. Cheng, D.T. Yegian, M.M. Miyasato, G.S. Samuelsen, R. Pellizzari, P. Loftus, C. Benson. Scaling and development of low-swirl burners for low-emission furnaces and boilers. Proc. Comb. Inst. 28 (2000) $1305-1313$. 
[6] M. Johnson, D. Littlejohn, W. Nazeer, K.O. Smith, R. K. Cheng. A comparison of the flow fields and emissions of high-swirl injectors and low-swirl injectors for lean premixed gas turbines. Proc. Comb. Inst. 30 (2005) 2867-2874.

[7] Cheng, R.K, Fable,S.A., Schmidt, D., Arellano, L., Smith, K.O.: Development of a low swirl injector concept for gas turbines. Proceedings of IJPGC 2001 International Joint Power Conference, New Orleans, Louisiana, USA,(2001)

[8] I.G. Shepherd, R.K. Cheng. The burning rate of premixed flames in moderate and intense turbulence. Combust. Flame 127 (2001) 2066-2075.

[9] R.K. Cheng, I.G. Shepherd, B. Bedat, L. Talbot. Premixed turbulent flame structures in moderate and intense isotropic turbulence. Combust. Sci. Technol. 174 (2002) 29-59

[10] R.K. Cheng, D. Littlejohn. Effects of combustor geometry on the flowfields and flame properties of a low-swirl injector. ASME Turbo Expo, Berlin, Germany, 393-407 (2008)

[11] R.K. Cheng, D. Littlejohn, W. Nazeer, K. Smith. Laboratory Studies of the Flow Field Characteristics of Low-Swirl Injectors for Adaptation to Fuel-Flexible Turbines. J. Eng. Gas Turb. Power 130 (2008) $21501-21511$.

[12] R.K. Cheng, D. Littlejohn, P. Strakey, T. Sidwell. Laboratory Investigations of Low-Swirl Injectors with $\mathrm{H} 2$ and CH4 at Gas Turbine Conditions. Proc. Comb. Inst. 32 (2009) 3001-3009.

[13] D. Littlejohn, R.K. Cheng, D.R. Noble, T. Lieuwen. Laboratory investigations of low-swirl injectors operating with syngases. J. Eng. Gas Turb. Power 132 (2010) 011502.

[14] M. Day, S. Tachibana, J. Bell, M. Lijewski, V. Beckner, R.K. Cheng. A combined computational and experimental characterization of lean premixed turbulent low swirl laboratory flames: I. Methane flames. Combust. Flame 159 (2012) 275-290

[15] P. L. Therkelsen, D. Littlejohn, R. K. Cheng. Parametric study of low-swirl injector geometry on its operability. ASME Turbo Expo 2012: Turbine Technical Conference and Exposition Volume 2:

Combustion, Fuels and Emissions, Parts A and B, Copenhagen, Denmark, 309-318 (2012).

[16] D.T. Yegian, R.K. Cheng. Development of a vane-swirler for use in a low NOx weak-swirl burner. American Flame Research Committee International Symposium, Baltimore, MD, (1996). 
[17] R.K. Cheng, S.A. Fable, D. Schmidt, L. Arellano, K.O.Smith. Development of a Low Swirl Injector Concept for Gas Turbines. Proceedings of IJPGC 2001 International Joint Power Conference, New Orleans, Louisiana, USA,(2001).

[18] D. J. Beerer. Combustion Characteristics and Performance of Low-Swirl Injectors with Natural Gas and Alternative Fuels at Elevated Pressures and Temperatures. Ph.D.thesis, (2013).

[19] T. Plessing, C. Kortschik, M.S. Mansour, N. Peters, R.K. Cheng. Measurement of the Turbulent Burning Velocity and the Structure of Premixed Flames on a Low Swirl Burner. Proc. Combust. Inst., 28 (2000) 359-366.

[20] H. C. De Lange, M. P. Houben, A. A.Van Steenhoven. Stereo-PIV Analysis of the low-swirl flow above a partial oxidation burner. Combust. Sci. Technol. 178 (2006) 1541-1557.

[21] D. Beerer, V. McDonell, P. Therkelsen, R. K. Cheng. Flashback and turbulent flame speed measurements in hydrogen/methane flames stabilized by a low-swirl injector at elevated pressures and temperatures. J. Eng. Gas Turb. Power,136 (2014) 1115-1123.

[22] M. Day, S. Tachibana, J. Bell, M. Lijewski, V. Beckner, R.K. Cheng. A combined computational and experimental characterization of lean premixed turbulent low swirl laboratory flames II. Hydrogen flames. Combust. Flame 162 (2015) 2148-2165.

[23] Y. B. Deng, X. Jiang, F.M. Su. Study on flow field characteristics of low swirl injector. Proceedings of ASME 2014 International Mechanical Engineering Congress \& Exposition, Montreal, Canada.(2014)

[24] S.C. Yang, L.C. Chen. Swirl generator with axial vanes, Industrial Technology Research Institute. United States Patent 5186607.

[25] A.G. Gaydon. Chapter 1- flame spectra. In: The spectroscopy of flames. pp.1-13. Academic, London (1974)

[26] A.G. Gaydon, H. G. Wolfhard. Chapter II- Premixed flames. In: Flames-Their structure, radiation and temperature. pp.7-40. Academic, London (1979) 